\title{
SOBRE EL PROBLEMA DE LA REALIDAD
}

No cabe discutir la existencia de lo que nos circunda, nos envuelve y en cierto modo nos limita. La realidad, en ese sentido, no constituye un problema. Que la metafísica, por su parte, recorra toda la gama de las soluciones especulativas posibles, está muy bien. Sobre todo porque el espíritu gana así en agilidad, en vigor crítico, en sutileza, en capacidad dialéctica y porque - apesar de los que desdeñan demasiado el argumento-el camino de la realidad es el argumento, siempre que se le conceda al hombre - esto es fundâmental-el derecho a superar la pura vida de los sentidos.

Para resolver la cuestión existencial de la realidad, basta el sentido común. La intuición inmediata nos muestra un mundo indefinido, que se nos opone sin que logremos evitarlo; en el cual somos apenas un punto insignificante, 1 mundo pleno de formas, $\mathrm{de}$ colores, de sonidos, que principia en nuestro más cerparió contornoşb se dilata más allá de las estrellas. Es el Universo de la extensión, que decía Pascal. El sentido común lo constata, lo vive ingenuamente; le confiere, sin adquirir de ello conciencia, individualidad propia, realidad, existencia. Sabe muy bien que las cosas son como son y que aún en la hipótesis de que la especie humana y con ella el pensamiento, se aniquilara, el espléndido panorama de las cosas continuaría existiendo sin sufrir la más leve alteración. ¿Qué importancia puede tener nuestra retina para asegurar la existencia propia de las realidades que recoje? ¿Qué le agrega nuestra visión a la belleza de una flor campesina, a la inmensidad majestuosa del mar, a la diáfana beatitud de los cielos? Entre el hombre y las cosas se abre, pues, un abismo, un abismo insondable, que la fantasía y el sentimiento religioso tratan de colmar. En este sentimiento, que llamaremos de distinción, reside precisamente el origen de toda actitud religiosa frente a la naturaleza; sentimiento de la naturaleza como existencia distinta.

Pero el problema de la realidad no es ya la cuestión existencial; sino esencialmente el problema de su interpretación. Cómo existe, porqué; éstas son las preguntas inquietantes. 
La simple constatación, la evidencia de que la realidad está dotada de una existencia independiente de la nuestra, no satisface al sentido común. La aventura especulativa le tienta y sale de sí mismo en pos de una fórmula metafísica interpretativa. El camino a las soluciones realísticas queda abierto de este modo. La inteligencia puesta al servicio de los sentidos, no tarda en suponer que debajo de la multiplicidad abigarrada de las cosas, se oculta un ánima invisible, no sólo diversa de la nuestra, sinó aún de sus propias manifestaciones. El sentido común no acepta ya, confiadamente, la ofrenda primigenia, el retazo luminoso que la naturaleza le pone en las manos graciosamente; antes, empieza a desconfiar de sus propias intuiciones hasta el extremo de rechazarlas, cuando no se ajustan estrictamente al esquema ideal o conceptual que le supone subyacente. Que se estudie con criterio histórico la filosofía griega y por muy poco que se ahonde, se advertirá en ella este proceso, cuyo punto de partida radica en la sensibilidad (filosofíía anterior a Sócrates), culminando en la trascendencia de las ideas platónicas y de la forma aristotélica. La sensibilidad es poco a poco reducida a un valor ínfimo y en cambio sobre sus despojos nace el culto a las abstracciones intelectuales cada vez más enrarecidas y anemiadas. que la Edad Media utilizó hábilmente en servicio de las doctrinas eclesiásticas.

Distante en el tiempo y en el espacio, sin embargo, la relación entre la más alta especulación y la menuda y complicada lógica que esgrimieron los escolásticos, es mas estrecha de lo que comunmente se cree. Nó porque los escolásticos continuaran aprovechando tranquilamente las fórmulas de la filosofía clásica; aporque reuty bien podían haberlas transformado al calor del espíritu cristiano sino porque apesar del nuevo espíritu, las formulas continuaron las mismas, ganando en abstracto formalismo lo que perdían en concreción. No obstante el escaso mérito que se quiera conferir a la filosofía medioeval (sin desconocer la existencia de grandes espíritus), podemos acercarla a la especulación griega, para deducir șemejanzas esenciales, que no para cansarnos enumerando diferencias. La ireductible actitud metafísica, que entraña la desvalorización del conocimiento sensible, ante todo, y después el naturalismo intelectualista que en la Edad Media contrasta con el espíritu del cristianismo, que es valorización del espíritu, precisamente, mientras el naturalismo prepara su desvalorización. Entrar en el análisis de estos elementos, complicaría enormemente la cuestión a diluci-
dar.

El sentimiento de distinción, en el seno del cual se originan las primeras tentativas de interpretación metafísica, contiene latente el germen de un sentimiento de la identidad, correspondiente a una tendencia espiritual más pura, más orgánica $y$, si se quiere, más positiva. No aparece antes ni después que el sentimiento de distinción; pero adquiere conciencia de su rol y de su importancia con tardía posterioridad. Con 
el cristianismo surge por primera vez en forma y con intensidad apreciable. El carácter mediador de Cristo, la doctrina de la caridad y el amor, la concepción ética y voluntarista de la existencia, expresan nada menos que la comunión íntima (en lo íntimo) de la realidad con el espíritu. Por desgracia este impulso original del cristianismo, desaparece en el devenir de los acontecimientos y sólo resurge con largas y penosas intermitencias, despojado ya de su primitiva prestancia maravillosa y virginal.

Por grados, desde el espontáneo impulso afectivo que guía amorosamente al hombre hácia la fraternidad con los objetos naturales, iluminados con un resplandor de belleza (il frate sole, la sora luna, il frate focu, la sorella allodola, que tan honda ternura despertaron en el alma de San Francisco), hasta la identificación metafísica donde la capacidad lógica se pone al servicio de exigencias folosóficas superiores, el sentimiento de identidad se incrementa y no cesa de acumular las razones de su propia justificación. La simpatía original que abre el corazón al viviente escenario del universo acaba por transmutarse en conciencia idealística, es decir, en sentimiento intelectualizado de la unidad esencial que, por debajo de la distinción aparente, vincula al hombre con la naturaleza. Así, de fría abstracción indiferente, todopoderosa y enemiga a veces, impersonal y misteriosa siempre, dueña de secretos designios' inquietantes, tórnase amical y fraterna, permeable sobre todo a los afectos humanos con los cuales comparte defectos y excelencias. Pero es lo nuestro, la naturaleza elevada hasta el plano de la humanidad, redimida de su torpeza y de su inconsciencia, a cuya sombra no germinan ya el pecadodyel nat.r L̀ humanidad, al mismo tiempo, adquiere una, significación cósmica, una conciencia creciente del señorío del espíritu en el universo, de su infinito "poder legislador indiscutible. Dondequiera encuentra un resplandor de si misma, y cuanto más simpatía, cuanto más fervor pone en el retazo de universo que contempla, tanto más fácilmente se reencuentra; incrementada, sí, y enriquecida con nuevas e insospechadas perspectivas.

El origen de toda actitud estética frente a la naturaleza, reside en este sentimiento de la identidad. La idea de la unidad esencial, desde que despierta en la conciencia, estimula nuestras virtualidades creadoras, ya desplegando la personalidad en imágenes estéticas, ya infundiéndole la plenitud de su potencia lógica y metafísica; pero conservando siempre el acento dinámico, activista y, por así decirlo, arbitrario que caracteriza la conciencia estética. Por eso el arte no es una mímesis, ni cabe una estética naturalista, porque contradice la esencia misma del arte, que es creación de realidad y no reproducción.

Porque el sentimiento de identidad se torna consciente con posterioridad al sentimiento de distinción, el idealismo aparece después que el realismo, significando en la historia de las ideas un verdadero e indiscutible progreso, así como el cristianismo auténtico significa un pro- 
greso con respecto a la especulación helénica y la lógica del principio de contradicción, creadora y dinámica, entraña un avance sobre la lógica aristotélica de la identidad. Entre una actitud pasiva, que contempla al mundo como una realidad distinta y extraña al pensamiento y que siguiendo la lógica natural de su porceso, concluye desvalorizándolo, para conferir a entidades abstractas las riquezas que los contenidos de la percepción de las cosas nos muetran directamente y una actitud eminentemente activa, que saca la realidad de su abstracción y la pone como momento necesario de su interna dialéctica, no es necesario acudir a sutilezas de metier filosófico para definir la superioridad. Basta advertir que el realismo obedeec a una visión ingenua de las cosas y que el llamado realismo crítico, cuya mejor defensa ha hecho Oswaldo Kulpe, en su obra Die Realiserung, no supera el realismo ingénuo sino en cuanto lo desvía hacia una actitud meiafísica (posición de objetos reales distintos de los objetos fenoménicos) que vuelve a plantear en toda su dificultad del dualismo de lo real que dejó sin solución la Crítica de la Razón Pura.

La identidad fundamental que el idealismo afirma entre el pensamiento y la realidad (naturaleza y espíritu), no equivale ciertamente a establecer un monismo abstracto en el cual se aniquila la existencia del mundo. Al contrario, es el reconocimiento y la mejor justificación de su existencia, siempre que no se excluya la distinción de la identidad y se confiera al objeto del conocimiento el papel que por esencia le corresponde, es decir, el significado de término opuesto al sujeto, indispensable a la correlación de la síntesis a priori en el sentido extrictamente kantiano. En otros términos 96 queles idéntico. debe ser distinto al mismo tiempo. Es idéntico el sujeto edon $\mathrm{Su}$ lobjetoo puesto que de otro modo es ininteligible la correlación. Pero debe ser también distinto, porque de no serlo no se daría la relación sujeto-objeto, sinó simplemente sujeto ó simplemente objeto; términos sin sentido, toda vez que no se les puede pensar siquiera sin vicularles una significación relativa. Son en cuanto existen ambos, en cuanto el sujeto es sujeto de un objeto y en cuanto el objeto es objeto de un sujeto. Rota la relación, desaparecen ambos términos. En suma, el problema del objeto, es decir, el problema de la realidad, el problema de nuestro no-ser, adquiere su máximo sentido filosófico en la concepción kantiana de la síntesis a priori, considerada, como quiere Gentile, verdaderamente a priori. Hay que partir, pues, de la síntesis, no de los términos que la integran. Esto es, poner en actividad como elemento primordial, anterior idealmente a sus resultados, el producirse antes que lo producido.

El realismo, igual que el idealismo subjetivo, desconoce la esencialidad de la síntesis a priori; pone, por consecuencia, uno solo de los términos y lo presupone a la existencia del otro. Pone la realidad como antecedente del espíritu. El idealismo subjetivo pone el sujeto 
como antecedente de la realidad, es decir, abstrae el pensamiento de las cosas y luego no sabe cómo deducir de él las cosas.

Ambos, idealismo subjetivo y realismo, quieren, partiendo de un término abstracto, ingresar en el otro, abstracto también; hilvanando aquí y allá retazos de universo, que muy difícilmente pueden esconder el artificio que los vincula. De allí los problemas insolubles, las cuestiones espeluznantes que impiden el acceso al campo de la filosofía profesional, bajo la amenaza de perder el tiempo dilucidando inextricables misterios de especulación, para salir, al final, con mayor suma de insatisfacción si cabe.

La síntesis a priori kantiana no es ciertamente síntesis de contrarios; Guido de Ruggiero lo ha hecho notar. Por eso no pudo deducir Kant las conclusiones lógicas de su idealismo trascendental. Es síntesis de idénticos y, por consecuencia, agota en sí misma sus virtualidades creadoras. Temperamento friamente científico, no tuvo Kant la emoción dramática del espíritu que informa la dialéctica de los contrarios, versión activista de la vida en la q' se ausenta definitivamente lo inmóvil, el elemento platónico que había nutrido los sistemas filosóficos hasta la aparición de Hegel. Los residuos de inmovilidad, así como los de trascendencia, que apesar del genio de Hegel, quedaron como cuerpos extraños en su sistema, han ido desapareciendo poco a poco gracias a la esforzada actividad crítica de sus continuadores, en un proceso muy vasto y muy intenso, rico en aportaciones novedosas y originales, que ha sido llamado el proceso de disolución del sistema hegeliano.

Las conclusiones idealistas que extrae de la reflexión y de la historia el esfuerzo filosófieo,Dnọtosimpider feliżmente continuar viviendo como realistas ingénūos desenvelyiendocpuestras actividades en la superficie de las cosas; pero acaso es necesario que alguna vez siquiera nos libertemos de la rutina cuotidiana y entremos en nosotros mismos y contemplemos con ojos maravillados el secreto de nuestra propia existencia, que es a pesar de los que deportan del universo el espíritu -el secreto de la existencia en general, de toda existencia y de todo valor.- 